\title{
Review
}

\section{Death and survival of neuronal and astrocytic cells in ischemic brain injury: a role of autophagy}

\author{
Min $\mathrm{XU}^{1,2}$, Hui-ling ZHANG ${ }^{1,2, *}$ \\ ${ }^{1}$ Department of Pharmacology and Laboratory of Cerebrovascular Pharmacology, College of Pharmaceutical Science, Soochow \\ University, Suzhou 215123, China; ${ }^{2}$ Suzhou Institute of Chinese Materia Medica, Suzhou 215007, China
}

\begin{abstract}
Autophagy is a highly regulated cellular mechanism that leads to degradation of long-lived proteins and dysfunctional organelles. The process has been implicated in a variety of physiological and pathological conditions relevant to neurological diseases. Recent studies show the existence of autophagy in cerebral ischemia, but no consensus has yet been reached regarding the functions of autophagy in this condition. This article highlights the activation of autophagy during cerebral ischemia and/or reperfusion, especially in neurons and astrocytes, as well as the role of autophagy in neuronal or astrocytic cell death and survival. We propose that physiological levels of autophagy, presumably caused by mild to modest hypoxia or ischemia, appear to be protective. However, high levels of autophagy caused by severe hypoxia or ischemia and/or reperfusion may cause self-digestion and eventual neuronal and astrocytic cell death. We also discuss that oxidative and endoplasmic reticulum (ER) stresses in cerebral hypoxia or ischemia and/or reperfusion are potent stimuli of autophagy in neurons and astrocytes. In addition, we review the evidence suggesting a considerable overlap between autophagy on one hand, and apoptosis, necrosis and necroptosis on the other hand, in determining the outcomes and final morphology of damaged neurons and astrocytes.
\end{abstract}

Keywords: autophagy; brain ischemia; hypoxia; neuron; astrocyte; apoptosis; necrosis

Acta Pharmacologica Sinica (2011) 32: 1089-1099; doi: 10.1038/aps.2011.50; published online 1 Aug 2011

\section{Introduction}

Autophagy is a highly regulated process involving the bulk degradation of cytoplasmic macromolecules and organelles in mammalian cells via the lysosomal system. In addition, autophagy is induced under starvation, differentiation, and normal growth control to maintain homeostasis and survival $^{[1-3]}$; however, it is also involved in neurodegenerative disorders and can trigger a form of programmed cell death (Type II death) distinct from apoptosis in neurons ${ }^{[4-7]}$. Accumulating evidence indicates that autophagy is activated and may be involved in the regulation of neuronal death in different animal models of ischemic brain injury, including hypoxiaischemia (HI) and global and focal ischemia ${ }^{[7-17]}$. Recently, using a permanent focal cerebral ischemia model of stroke and an oxygen and glucose deprivation (OGD) model in primary cultured astrocytes, the authors show that autophagy is activated in ischemic astrocytes and contributes to astrocytic cell death $^{[18]}$. Therefore, in this review, we systematically discuss the activation of autophagy during cerebral ischemia and/

\footnotetext{
* To whom correspondence should be addressed.

E-mail huilingzhang07@hotmail.com

Received 2010-11-22 Accepted 2011-04-08
}

or reperfusion not only in neurons but also in astrocytes, the role of autophagy in neuronal and astrocytic cell death and survival, and the mechanisms of autophagy activation and its regulation. In addition, we review what is known about the crosstalk between autophagy and apoptosis, between autophagy and necrosis, and between autophagy and necroptosis in determining the outcomes and final morphology of damaged neurons and astrocytes.

\section{Different types of neural cell death in the ischemic region}

There are three types of neural programmed cell death (PCD) induced by cerebral ischemic and/or hypoxic injury: (1) necrosis, (2) apoptosis, and (3) autophagy.

Neuronal cell death following cerebral ischemia has traditionally been termed necrosis. Necrosis is the end result of a bioenergetic catastrophe that results from ATP depletion to a level incompatible with cell survival and is thought to be initiated mainly by cellular "accidents," such as toxic insults or physical damage (Figure 1E). In contrast to apoptosis, necrosis has traditionally been thought to be a passive form of cell death with more similarities to a train wreck than a suicide. However, recent research has found that necrosis 


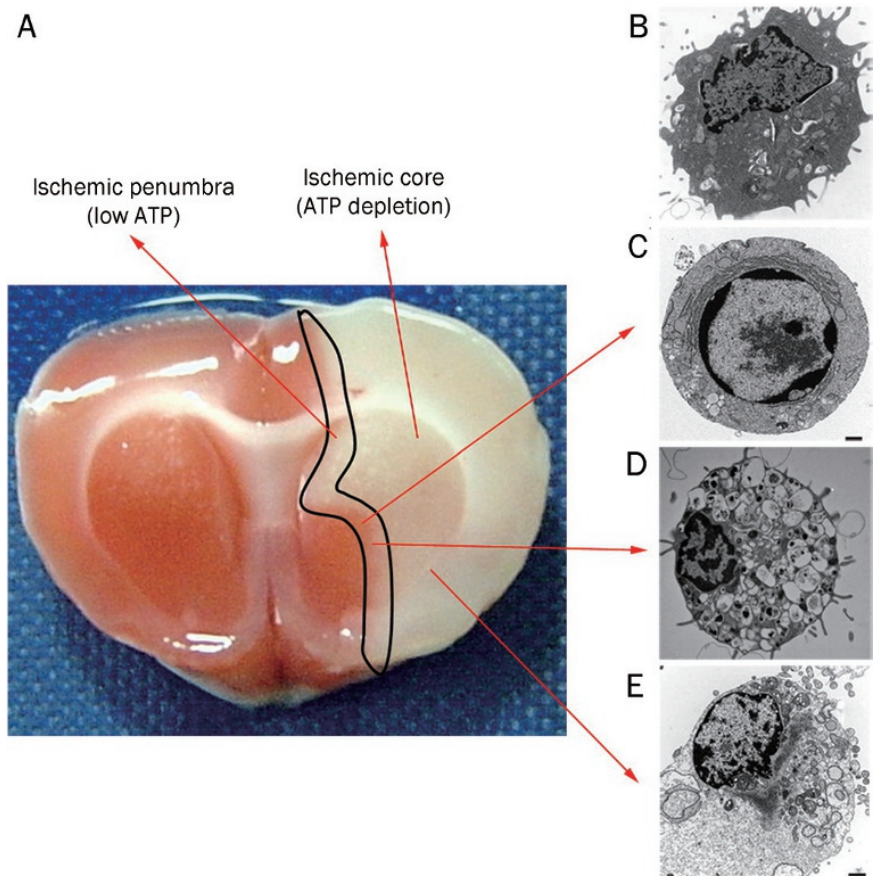

Figure 1. Necrosis, apoptosis and autophagy in focal cerebral ischemia. A: TTC staining showing the ischemic core region (white color) and the ischemic penumbra (periinfarct, A). B, C, D, and E: Electron micrographs ${ }^{[82]}$. Necrosis is predominant in the ischemic core, whereas apoptosis and autophagy are often observed in the penumbra after focal cerebral ischemia. The main morphological characteristics of necrosis are the vacuolation of the cytoplasm and the breakdown of the plasma membrane (E). Morphologically, apoptosis is characterized by nuclear and cytoplasmic condensation and cellular fragmentation into apoptotic bodies (C). Morphological characteristics of autophagy include vacuolization, degradation of cytoplasmic contents, and slight chromatin condensation (D). B: Normal cell.

is not merely an accident. When caspases were originally identified as the mediators of apoptosis, it was hypothesized that many of their substrates were essential proteins whose destruction ensured the inevitability of cell death. However, caspase-independent cell death is observed in many systems where cells still die even if the executioner is absent. Following an apoptotic stimulus, such as the expression of Bax or treatment with tumor necrosis factor (TNF) or Fas ligand (FasL), the cells will die even in the presence of non-specific caspase inhibitors, such as zVAD-fmk (benzyloxycarbonylVal-Ala-Asp(OMe)-fluoromethylketone), or antiapoptotic molecules, such as Bcl-xL, that prevent caspase activation ${ }^{[19,20]}$. Under these conditions, the cells that would normally die by apoptosis exhibit all the hallmarks of necrosis. In some cases, caspase-independent necrotic cell death can be forestalled by treatment with antioxidants or by eliminating the activity of the protein kinase receptor-interacting protein (RIP). These results lead to the idea that necrosis could be "programmed" cellular signaling events that initiate necrotic destruction and could be blocked by inhibiting discrete cellular processes. In 2005, Yuan et al at Harvard University termed "programmed necrosis" as necroptosis.

Apoptosis is a process of cell suicide regulated by different cell signaling pathways, which consists of a series of biochemical events including cell shrinkage, chromatin condensation, and formation of cytoplasmic blebs and fragmentation of nuclear DNA into membrane-bound structure, called "apoptotic bodies", that contain the contents of the cell (Figure 1C). At the biochemical level, apoptosis of mammalian cells is characterized by phosphatidylserine exposure and effector caspase activation, the main executors of apoptotic cell death. Studies have proven that delayed cell death induced by cerebral ischemia is apoptotic.

Autophagy is a dynamic and carefully regulated process for the intracellular maintenance of proteins, lipids, and aging organelles ${ }^{[21-23]}$. It is characterized by the formation of autophagic vesicles in the cytoplasm, which contain a great deal of cellular components (macromolecules and organelles, Figure 1D). The degradation of the Golgi apparatus, polyribosomes and endoplasmic reticulum (ER) occurs earlier than nuclear disintegration. During this process, intact mitochondria provide autophagy with the required energy. Research shows that a well-preserved cytoskeleton structure is necessary for autophagic degradation. It has become increasing clear that necrosis predominates in the ischemic core (Figure 1A), whereas apoptosis and autophagy are often observed in the penumbra (Figure 1A) after cerebral ischemia.

Although the roles of apoptosis and necrosis in ischemic and/or hypoxic brain injury have been studied intensively, the implication of autophagic cell death has only recently been considered.

\section{Autophagy is activated in ischemic and/or hypoxic damaged brain tissue}

In recent years, through the use of electron microscopy, immunohistochemistry and Western blots, scholars have confirmed from morphological and biochemical evidence that autophagy is activated in the damaged brain tissue in animal models of ischemic and/or hypoxic cerebral injury, including the transient global cerebral ischemia model, hypoxia-ischemia (HI) model and focal cerebral ischemia model (Table 1). The first hint of autophagy activation dates back to 1995, when using electron microscopic analysis in a transient global cerebral ischemia model in gerbils, researchers found that the volume density of cathepsin B-positive lysosomes markedly increased $3 \mathrm{~d}$ after the ischemic insult, while that of autophagic vacuolelike structures also increased at this stage, suggesting that the cathepsin B-immunopositive lysosomes that increase in the neurons after ischemic insult are mostly autolysosomes. Further studies have demonstrated that the delayed death of the CA1 pyramidal neurons after brief ischemia is not necrotic but apoptotic $^{[8]}$. However, before 2005, there are relatively few examples of neuronal death that meet the necessary morphological criteria of autophagy. One possible reason is that, until recently, sensitive markers for autophagy, similar to those existing for apoptosis, have not been available. Currently, there is increasing interest in whether autophagic cell death 
Table 1. Autophagy is activated after ischemic (hypoxic) brain injury.

\begin{tabular}{|c|c|c|c|c|}
\hline Model & Sites & Autophagy activation marker & Lysosome activation marker & $\begin{array}{l}\text { Refer- } \\
\text { ence }\end{array}$ \\
\hline $\begin{array}{l}\text { Transient global cerebral } \\
\text { ischemia in gerbils }\end{array}$ & $\begin{array}{l}\text { Damaged hippocam- } \\
\text { pus }\end{array}$ & $\begin{array}{l}\text { Electron microscopy: autophagic vesicle- } \\
\text { like structure in the cytoplasm } \uparrow\end{array}$ & $\begin{array}{l}\text { Electron microscopy: the volume density of } \\
\text { cathepsin B-positive lysosomes } \uparrow\end{array}$ & $f$ [8] \\
\hline Ischemia-hypoxia in mice & Damaged brain tissue & Western blot: LC3-II $\uparrow$ & & $\begin{array}{l}{[9]} \\
{[10]}\end{array}$ \\
\hline Ischemia-hypoxia in mice & Damaged brain tissue & $\begin{array}{l}\text { Electron miroscopy: autophagic vesicle } \uparrow \\
\text { Immunofluorescence: punctate GFP-LC3 } \\
\text { Western blot: LC3-I }\end{array}$ & & [11] \\
\hline $\begin{array}{l}\text { Ischemia-hypoxia in neo- } \\
\text { natal rats }\end{array}$ & $\begin{array}{l}\text { Damaged cortex and } \\
\text { hippocampus }\end{array}$ & $\begin{array}{l}\text { Immunohistochemistry and Western blot: } \\
\text { beclin1 in the neurons } \uparrow\end{array}$ & & [12] \\
\hline $\begin{array}{l}\text { Ischemia-hypoxia in neo- } \\
\text { natal rats }\end{array}$ & Damaged brain tissue & $\begin{array}{l}\text { Electron microscopy: autophagic vesicle } \uparrow \\
\text { Immunohistochemistry and Western blot: } \\
\text { LC3-II } \uparrow \text {; or punctate GFP-LC3 }\end{array}$ & 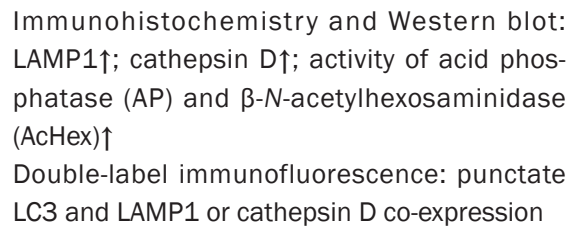 & : \\
\hline $\begin{array}{l}\text { Ischemia-hypoxia in neo- } \\
\text { natal mice (Atg7 deficit) }\end{array}$ & Damaged brain tissue & $\begin{array}{l}\text { Electron microscopy: autophagic vesicle } \uparrow \\
\text { Immunohistochemistry and Western blot: } \\
\text { LC3-II } \uparrow \text {; or punctate GFP-LC3 }\end{array}$ & & {$[7]$} \\
\hline $\begin{array}{l}\text { Permanent middle cere- } \\
\text { bral artery occlusion in } \\
\text { rats }\end{array}$ & Damaged brain tissue & $\begin{array}{l}\text { Electron microscopy: autophagic vesicle } \uparrow \\
\text { autolysosome } \uparrow \\
\text { Western blot: LC3-II } \uparrow\end{array}$ & $\begin{array}{l}\text { Electron microscopy: darkened lysosomes } \\
\text { Western blot: cathepsin } \mathrm{B} \uparrow\end{array}$ & [ [17] \\
\hline $\begin{array}{l}\text { Transient middle cere- } \\
\text { bral artery occlusion in } \\
\text { mice }\end{array}$ & Damaged brain tissue & Western blot: LC3-II $\uparrow$ & & [14] \\
\hline $\begin{array}{l}\text { Transient middle cerebral } \\
\text { artery occlusion in rats } \\
\text { (ischemia/reperfusion) }\end{array}$ & $\begin{array}{l}\text { Neurons in damaged } \\
\text { brain tissue and peri- } \\
\text { infarct }\end{array}$ & 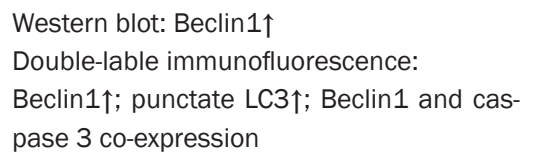 & & [15] \\
\hline $\begin{array}{l}\text { Transient middle cerebral } \\
\text { artery occlusion in neo- } \\
\text { natal mice (ischemia/ } \\
\text { reperfusion) }\end{array}$ & $\begin{array}{l}\text { Damaged brain tissue } \\
\text { and periinfarct }\end{array}$ & $\begin{array}{l}\text { Electron microscopy: autophagic vesicle } \uparrow \\
\text { Immunohistochemistry: punctate LC3 } \uparrow\end{array}$ & 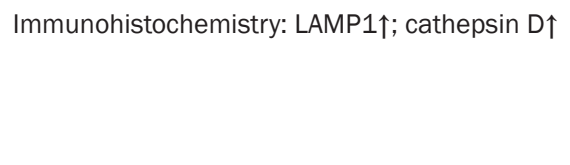 & [16] \\
\hline $\begin{array}{l}\text { Permanent middle cere- } \\
\text { bral artery occlusion in } \\
\text { rats }\end{array}$ & $\begin{array}{l}\text { Astrocytes in damaged } \\
\text { brain tissue }\end{array}$ & $\begin{array}{l}\text { Electron microscopy: autophagic vesicle } \uparrow \\
\text { autolysosome } \uparrow \text {; lysosome } \uparrow\end{array}$ & & [18] \\
\hline $\begin{array}{l}\text { Oxygen-glucose depriva- } \\
\text { tion in primary cultured } \\
\text { astrocytes }\end{array}$ & $\begin{array}{l}\text { Primary cultured brain } \\
\text { cortex astrocytes }\end{array}$ & 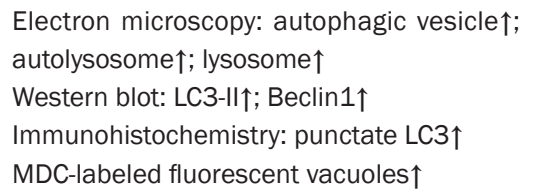 & Western blot: cathepsin B $\uparrow, \mathrm{LAMP} 2 \uparrow$ & [18] \\
\hline
\end{tabular}

might be involved in the regulation of neuronal or astrocytic cell death after ischemia, especially after ischemic-hypoxic and focal cerebral ischemic injury.
The activation of autophagy induced by $\mathrm{HI}$ has been intensively investigated. The extent of ischemic-hypoxic injury depends on the degree of maturation of the brain as well as 
on the severity and duration of the insult ${ }^{[24-30]}$. Neurons in the immature brain can tolerate a longer period of oxygen deprivation and/or ischemia than the neurons in the adult brain $^{[25,27]}$. However, there are conflicting reports that show that the immature brain is less resistant to ischemic-hypoxic brain damage than its adult counterpart ${ }^{[28]}$. Furthermore, clinical data suggest that outcome and mortality after acute cerebral injury are age-dependent, with more severe injuries in infants than in adults ${ }^{[31,32]}$. In 2005, Zhu et al have found that after unilateral $\mathrm{HI}$, the autophagosome-related marker microtubule-associated protein 1 light chain 3-II (LC3-II) is three times more pronounced in adult brains, compared with immature brains, indicating for the first time that autophagy is involved in delayed cell death after cerebral ischemia ${ }^{[9]}$. Sexrelated differences in cerebral injury and outcome following cerebral stroke or trauma have been considered attributable to the differences in brain structure and function induced by estrogen $^{[33]}$. In 2006, another report from Zhu et al showed that there are no sex differences in cerebral injury and LC3-II increases after a severe ischemic-hypoxic insult in neonatal mice, suggesting that there is no sex dependence in the induction of autophagy after neonatal $\mathrm{HI}^{[10]}$. Additionally, in 2006, using a modified Levine/Vannucci procedure in adult mice that consists of unilateral common carotid artery occlusion and hypoxia, Adhami et al demonstrated that at the tissue level, HI causes persistent cerebral perfusion deficits even after release of the carotid artery occlusion, which is associated with both platelet deposition and fibrin accumulation within the cerebral circulation ${ }^{[11]}$. At the cellular level, caspase- 3 is not activated, and very few cells completed the apoptotic process. Instead, many damaged neurons show features of autophagic/lysosomal cell death. Together, these results suggest that $\mathrm{HI}$ is a powerful stimulus for spontaneous coagulation leading to reperfusion deficits and autophagic/lysosomal cell death in the brain. In 2008, Carloni et al showed that the autophagy marker, Beclin1, is significantly increased a short time after HI, both in the hippocampus and in the cerebral cortex in the neonatal cerebral HI model ${ }^{[12]}$. More recently, Ginet $e t$ al provide strong evidence that severe $\mathrm{HI}$ increases not only autophagosomal abundance (increase in LC3-II) but also lysosomal activities (cathepsin D, acid phosphatase, and $\beta$-N-acetylhexosaminidase) in the cortex and hippocampus, demonstrating an increase in autophagic flux ${ }^{[13]}$.

Increasing evidence demonstrates that autophagy is also activated in damaged brain tissue after focal cerebral ischemia (Table 1). The evidence comes from a 2005 study showing that the expression of autophagy marker LC3-II is increased in damaged brain tissue after transient middle cerebral artery occlusion (tMCAO) in mice ${ }^{[14]}$. In 2008, by morphological and biochemical analysis, we have confirmed that focal cerebral ischemia activates the autophagosome/lysosome pathway using a rat model of permanent middle cerebral artery occlusion (pMCAO). Electron microscopic analysis has revealed that autophagosomes and autolysosomes are significantly increased in neuronal cytoplasm in the ischemic cortex after pMCAO in rats. Western blot analysis also has shown that the expression of LC3-II and cathepsin B (a main lysosomal protease of the brain parenchyma) are increased in the ischemic cortex $^{[17]}$. These observations are also supported by Rami et $a l$, who showed that a dramatic elevation in Beclin1 and LC3 levels in the penumbra of rats challenged by $\mathrm{tMCAO}^{[15]}$, and by Puyal et al, who indicated that lysosomal and autophagic activities are increased in the ischemic neurons after transient focal cerebral ischemia ${ }^{[16]}$.

\section{In which cells is autophagy activated in the ischemic region?}

Autophagy is activated in neurons in the ischemic region

Accumulating evidence detected by electron microscopic and immunohistochemical analysis shows that autophagy is activated in neurons in the ischemic cerebral tissue in different animal models of ischemic and/or hypoxic cerebral injury, including the transient global cerebral ischemia model, $\mathrm{HI}$ and the focal cerebral ischemia model (Table 1).

\section{Evidence from electron microscopy is as follows:}

With electron microscopy, the intense vacuolization and numerous autophagosomes are observed in neurons in the ischemic region ${ }^{[8,11,13,17]}$. More importantly, in an adult mouse $\mathrm{HI}$ model, the activation of autophagy in different degrees of neuronal injury has been examined in detail. Cortical neurons on the challenged side show vacuole-associated damage ranging from cells harboring multiple cytoplasmic vacuoles (Figure 2C) to cells completely lacking cytoplasmic contents (Figure $2 \mathrm{~F}$ ). There is also diffuse myelin degeneration and loss of synapses (Figure 2, compare B with G). In less damaged neurons, judging from the morphology of healthy mitochondria, there are many vacuole-related structures containing electron-dense material (Figure 2D, avd) or whorls of membranous material (Figure 2D and 2E; avm). More severely damaged neurons show condensed chromatin in the nucleus, cup-shaped endoplasmic reticulum fragments, swollen mitochondria, and vacuoles that contain little material (Figure 2G, asterisk) in the cytoplasm. Moreover, many severely damaged neurons exhibit a shrunken nucleus with condensed chromatin surrounded by an extensively lysed cytoplasm but retain an intact plasma membrane (Figure 2F). These morphological features are not typical of apoptosis or necrosis. Instead, they suggest an induction of the autophagosomal-lysosomal compartment of programmed cell death ${ }^{[11]}$. Furthermore, the time point changes of the activation of autophagy/lysosome in neurons after ischemia has been revealed by electron microscopy by finding autophagosomes and autolysosomes that appear in neurons as early as $1 \mathrm{~h}$ after pMCAO and continue to increase from 3 to $12 \mathrm{~h}$. Sometimes, autophagosomes with engulfed organelles are found. At $6 \mathrm{~h}$ after ischemia, damaged neurons display fragmented ER membranes and condensed chromatin. At $24 \mathrm{~h}$ after ischemia, cell shrinkage, large chromatin clumps, nuclear condensation/fragmentation, swollen cytoplasm, damaged organelles and deteriorated membranes co-exist in the same neuron ${ }^{[17]}$. In addition, intense vacuolization and numerous autophagosomes appear at $6 \mathrm{~h}$ post-HI and are 

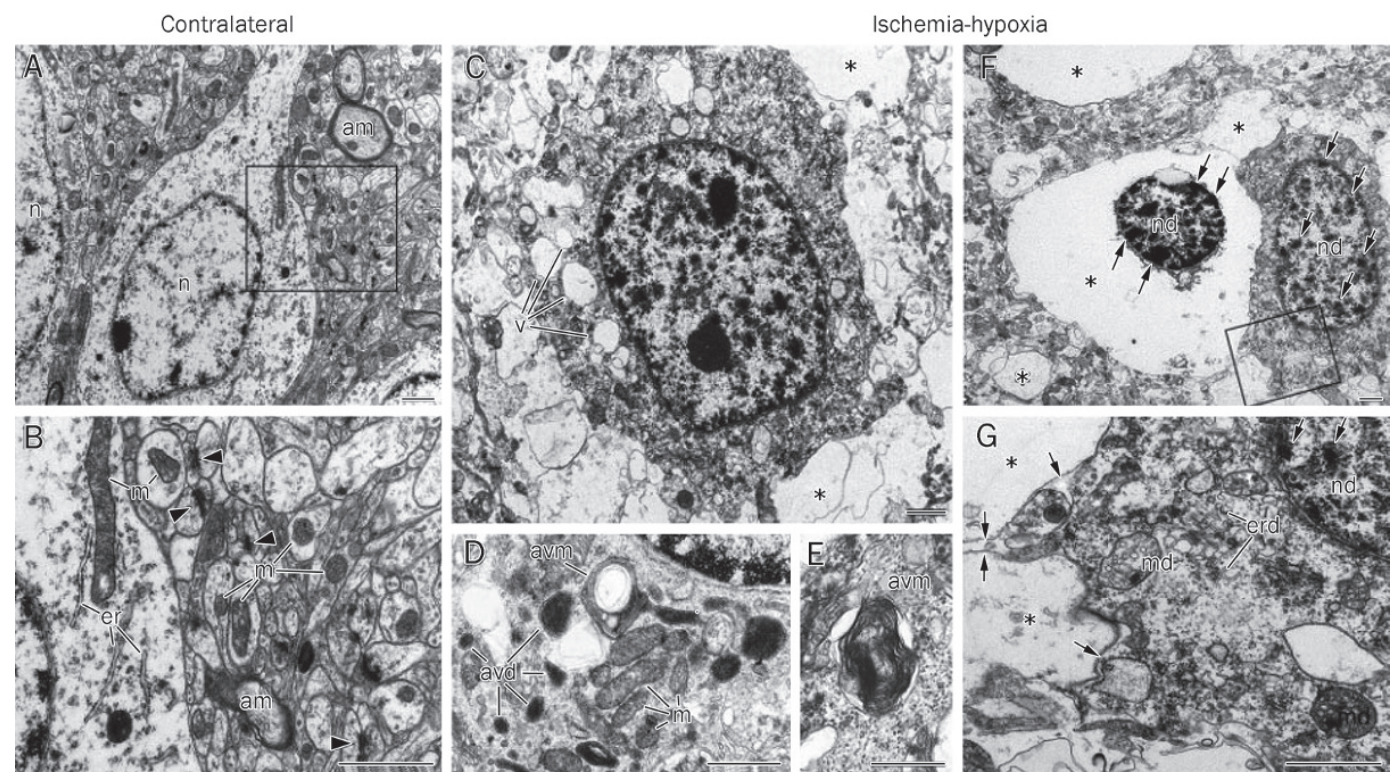

Figure 2. Ischemia-hypoxia induces vacuolization and lysis of cellular organelles. A and B: Contralateral hemisphere illustrates normal structures of neuronal cell bodies and the neuropil. Notice homogenous nuclear chromatin ( $n$ ), myelinated axons (am), intact mitochondria ( $m$ ), cisterns of endoplasmic reticulum (er), and numerous synapses (arrowheads). C-G: Damaged neurons in the cerebral cortex at $6 \mathrm{~h}$ after ischemia-hypoxia show multiple vacuoles ( $\mathrm{v}$ in $\mathrm{C}$ ) in the cytoplasm and different degrees of cell destruction. Electron micrographs of the cytoplasm in less damaged neurons ( $D$ and $\mathrm{E}$; notice intact mitochondria, $\mathrm{m}$ ) exhibit autophagy-like vacuoles containing electron-dense material (avd) and whorls of membranous material (avm). In more advanced cell destruction, many cells demonstrate the near-complete lysis of organelles (asterisks in C, F, and G), but the plasma membrane of such cells is preserved (arrows in $\mathrm{G}$ ). Moderately damaged cells $(\mathrm{G})$ display fragmented endoplasmic reticulum membranes (erd), condensed chromatin (double arrows) in damaged nuclei (nd), and swollen mitochondria (md) containing an electron transparent matrix. Condensation of chromatin (double arrows in $\mathrm{F}$ and $\mathrm{G}$ ) in damaged nuclei might be the result of a proapoptotic reaction or represent aborted apoptosis. $\mathrm{B}$ and $\mathrm{G}$ represent the enlarged framed areas in $A$ and F, respectively. Scale bars: $1 \mu \mathrm{m}(\mathrm{A}-\mathrm{C}, \mathrm{F}, \mathrm{G}) ; 0.5 \mu \mathrm{m}(\mathrm{D}, \mathrm{E})$. Used with permission from Adhami et al whose original article was published in the American Journal of Pathology, Volume 169, Issue 2, August 2006, Pages 566-583 (Copyright (c) 2006 American Society for Investigative Pathology Published by Elsevier Inc) $)^{[11]}$.

more abundant at $24 \mathrm{~h}$ in the dying neurons ${ }^{[13]}$.

\section{Evidence from double immunolabeling was observed as follows:}

An increase in punctate LC3 or Beclin1 is observable in the ischemic neurons by double immunolabeling ${ }^{[12,13]}$. This increase in the expression of autophagy markers mainly occurs in the border of the lesion but also in some neurons inside of the lesion ${ }^{[13]}$.

\section{Autophagy is activated in astrocytes in the ischemic region}

Whether autophagy is activated in astrocytes in ischemic brain injury and contributes to astrocytic cell death is largely unknown. More recently, using a rat model of $\mathrm{pMCAO}$ in vivo and OGD in primary cultured astrocytes in vitro, the authors have dynamically observed that autophagosomes appear in the cytoplasm of astrocytes in both the ischemic cortex $1 \mathrm{~h}$ after pMCAO and the primary astrocytes $1 \mathrm{~h}$ after OGD. The most abundant autophagosomes are observed $3 \mathrm{~h}$ after pMCAO and OGD. The number of lysosomes is significantly increased $6 \mathrm{~h}$ after pMCAO and OGD. Both apoptotic and necrotic morphological features are seen in the same astrocytes 12-24 h after pMCAO and OGD. Autophagic vacuole analysis with MDC (monodansylcadaverine) staining shows that a large number of fluorescent particles appears in the astrocytes $0.5 \mathrm{~h}$ after $\mathrm{OGD}^{[18]}$ and reaches a peak at $3 \mathrm{~h}$ (Figure 3 ). Western blot analysis in primary cultured astrocytes after OGD
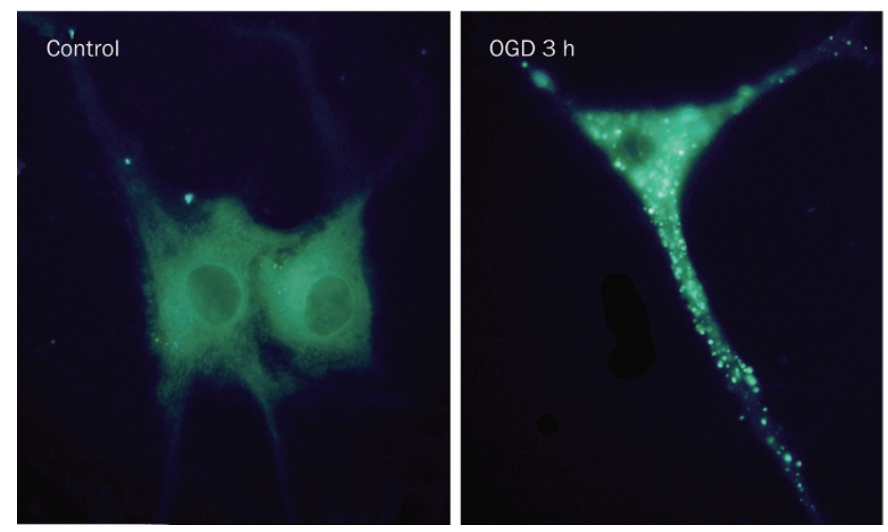

Figure 3. Increased autophagic vacuoles in primary astrocytes after OGD injury. Astrocytes were cultured and labeled with MDC. Representative MDC staining shows MDC-labeled vesicles in the cytoplasm, perinuclear regions and neurites $3 \mathrm{~h}$ after OGD, indicating the increased formation of autophagic vacuoles in astrocytes. 
demonstrates that autophagy-related proteins LC3 and Beclin1 as well as the lysosomal-related protein cathepsin B and the lysosome associated membrane protein 2 (LAMP2) increase in the injured astrocytes. Taken together, the autophagy/lysosome pathway (ALP) is activated in the ischemic astrocytes in both in vivo and in vitro ischemic or hypoxic models ${ }^{[18]}$.

Autophagy is activated in endothelial cells in the ischemic region Autophagy activation has recently been implicated in endothelial cells in the ischemic region. Many blood vessels in the peri-infarct region show a higher level of GFP (green fluorescent protein)-LC3 expression and punctate GFP-LC3 dots in the endothelial cells at $18 \mathrm{~h}$ in the HI-induced GFP-LC3 transgenic mice ${ }^{[11]}$.

\section{Mechanisms of autophagy activation in ischemic and/or hypoxic brain injury}

Ischemic brain injury causes death in both neurons and astrocytes $^{[34]}$. Calcium-overload, excitotoxicity, ER stress and oxidative injury, and caspase-mediated apoptosis have been implicated as major injury mechanisms ${ }^{[35,36]}$.

\section{ER stress and oxidative stress}

Previous reports have demonstrated that the ER is involved in ischemic neuronal cell death, protein synthesis inhibition ${ }^{[37,38]}$, phosphorylation of phospho-extracellular signal-regulated kinase (PERK) ${ }^{[39]}$ and eukaryotic initiation factor 2 alpha $(\mathrm{eIF} 2 \mathrm{\alpha})^{[40]}$, depletion of the ER calcium pool ${ }^{[41]}$, accumulation of unfolded proteins in the $\mathrm{ER}^{[42]}$, and induction of the ER molecular chaperone ${ }^{[43]}$. An increasing number of studies indicates that autophagy is induced by ER stress in organisms from yeast to mammals ${ }^{[44,45]}$. Hypoxia activates the ER-resident translation initiation factor eIF2 $\alpha$ and PERK, and eIF2 $\alpha$ kinase regulates starvation- and virus-induced autophagy.

Another common intracellular stress that effectively leads to the induction of autophagy is oxidative stress. More recently, it has been demonstrated that oxidative stress activates autophagy in dopaminergic neuronal cell lines and cultured primary astrocytes ${ }^{[46-48]}$. Together, ER stress and oxidative stress may be important mechanisms of autophagy activation in ischemic brain injury. However, there is still a lack of direct evidence.

\section{Excitotoxicity}

Glutamate excitotoxicity mediated by $N$-methyl- $D$-aspartic acid (NMDA) receptor activation plays a key role in many aspects of cerebral ischemic injury. Excitotoxicity is the basis for necrotic cell death in the ischemic core and the initiator of programmed cell death in the ischemic penumbra. NMDA agonists induce the activation of autophagy in damaged neurons in the striatum ${ }^{[49]}$. Excitotoxicity-mediated activation of autophagy may be associated with the activation of the c-Jun N-terminal kinase (JNK) signaling pathway, which is one of the most important NMDA receptor-mediated signal pathways. JNK are mitogen-activated protein kinases encoded by three genes: $J n k 1, J n k 2$, and $J n k 3^{[50]}$. Each gene is alternatively spliced to produce one or two variants of 46 and $54 \mathrm{kDa}$, which generates a total of at least 10 JNK isoforms with potentially different pro-survival and pro-death roles ${ }^{[51]}$. Among its pro-death roles, JNK has been shown to be important for neuronal death after excitotoxic stress because of its involvement in necrosis and apoptosis ${ }^{[52-54]}$. In cerebral ischemia, JNK has become an accepted target for neuroprotection because small-molecule inhibitors ${ }^{[55]}$ or cell-penetrating peptides ${ }^{[56,57]}$ such as D-JNKI1 (d-c-Jun N-terminal kinase 1 inhibitor), a cell-permeable peptide inhibitor of the JNK pathway, have been shown to be a powerful neuroprotective agent after focal cerebral ischemia in adult mice and young rats. D-JNKI1 has also been found to have a potential neuroprotective effect in a clinically relevant model of neonatal cerebral $\mathrm{HI}$ and to reduce autophagosome formation in the thalamus, suggesting that the JNK signaling pathway involves HI-induced autophagic cell death $^{[58]}$

\section{Contributions of autophagy activation to neural cell survival and death in ischemic and/or hypoxic cerebral injury \\ Mild or moderate activation of autophagy promotes neural cell survival}

Autophagy plays a key role in neuronal survival. Knockout mouse studies targeting Atg5 or Atg7 elegantly demonstrate that neurons require at least basal levels of autophagy for the maintenance of health and function in vivo ${ }^{[59,60]}$. 3-methyladenine (3-MA) and wortmannin, two inhibitors of autophagy, dramatically reduce Beclin1 expression and switch the mechanism of cell death modes from apoptosis to necrosis. Conversely, rapamycin, an inducer of autophagy, augments Beclin1 expression, diminishes necrotic cell death, and decreases brain injury after neonatal HI. A prophylactic treatment with simvastatin or hypoxic preconditioning also upregulates Beclin1 expression. Taken together, these data indicate that autophagy is increased in neuronal cells after neonatal $\mathrm{HI}$ and suggest that the activation of autophagic pathways represents a potential protective mechanism in the early stages of brain injury ${ }^{[12]}$. Elevated amounts of caspase-3-positiveand Beclin1-positive cells have been found in the penumbra of rats challenged by cerebral ischemia at 6-24 h. However, not all caspase-3-positive cells are also Beclin1-positive and not all Beclin1-expressing cells are caspase-3-positive. Semiquantitative assessment shows that approximately $30 \%$ of cells in the penumbra present both the activation of caspase- 3 and the up-regulation of Beclin1, indicating that Beclin1 may possess a repair function via autophagy ${ }^{[15]}$.

\section{Overactivation of autophagy promotes neural cell death}

Theoretically, autophagic cell death is caused by lysosomal enzymes; thus, we and other scholars hypothesize that persistent or severe cerebral ischemia overactivates autophagy, which causes cell self-digestion and induces neural cell death. Emerging evidence indicates that ALP activation induced by focal cerebral ischemia contributes to neuronal cell death. Cerebral ventricular microinjection of 3-MA, bafilomycin 
A1 [Baf, a specific inhibitor of vacuolar-type $\mathrm{H}(+)$-ATPases], which inhibits fusion between autophagosomes and lysosomes, or Z-FA-fmk (benzyloxycarbonyl-phenyl-alanylfluoromethylketone, a cathepsin $\mathrm{B}$ and $\mathrm{L}$ inhibitor) reduces cerebral infarct volume, decreases brain edema and improves neurological deficits. In addition, 3-MA can largely reduce infarct volume even administered $4 \mathrm{~h}$ after ischemia, indicating 3-MA has a wide therapeutic window. Furthermore, 3-MA and Baf significantly reduce the death of astrocytes and play a protective role in astrocytic injury induced by cerebral ischemia in a rat model of pMCAO in vivo and in OGD-induced primary cultured astrocytes in vitro ${ }^{[18]}$. These neuroprotective effects are associated with the inhibition of the up-regulation of LC3-II and cathepsin B in the rat brain or primary cultured astrocytes challenged by cerebral ischemia or OGD. These studies strongly suggest that ALP is activated not only in ischemic neurons, but also in ischemic astrocytes and participates in the demise of neurons and astrocytes. Notably, 3-MA and Baf may have diverse effects on neural cells that extend beyond autophagy regulation to include the modulation of survival/death kinases by 3-MA. Thus, the issue of whether autophagy observed in dying neural cells reflects a death mechanism, failed adaptation, or epiphenomenon requires additional approaches to establish causality. The identification of autophagy $(\mathrm{Atg})$ genes involved in specific ubiquitinlike conjugation reactions that are essential for the extension of autophagic membranes has revolutionized the field, allowing for the development of specific markers for autophagic vacuole formation and maturation and providing molecular genetic tools for knocking out or knocking down essential Atg gene products. Recently, evidence on the genetic level showing that ribonucleic acid interference (RNAi)-mediated downregulation of Beclin1 decreases infarct volume and inhibits histological injury and neurological deficits induced by focal cerebral ischemia ${ }^{[6]]}$ supports the present conclusion.

In addition, ALP activation induced by severe $\mathrm{HI}$ also contributes to neuronal cell death. The direct evidence comes from neuron Atg7-deficient neonatal mice showing strong neuroprotection $7 \mathrm{~d}$ after $\mathrm{HI}$ injury ${ }^{[62]}$.

The next issue we need to resolve is which modes of neural cell death ALP activation is involved in.

\section{ALP activation is involved in cerebral ischemia-induced pure autophagic programmed cell death}

The morphological characteristics of autophagic programmed cell death can be observed by electron microscopy in the adult mouse HI model by Adhami et $a l^{[11]}$ and in a rat model of pMCAO by Qin et al ${ }^{[18]}$, suggesting that cerebral ischemia and/or hypoxia may induce pure autophagic programmed cell death (See Figure 2 for more details).

\section{ALP activation participates in cerebral ischemia-induced apopto- sis}

A defining biochemical feature of apoptosis is the requirement for caspases acting through one of two general pathways. An intrinsic pathway, commonly used by neurons, relies on mitochondria for the release of apoptotic factors (cytochrome $c$ and Smac/Diablo) that activate the initiator caspase-9 and downstream effector caspases. An extrinsic pathway, initiated by extracellular death ligands $(e g$, tumor necrosis factor and Fas), activates effector caspases via the initiator caspase- 8 and caspase- 10 and additionally via crosstalk with the mitochondrial pathway ${ }^{[63]}$. It has been demonstrated that the activation of downstream caspase-3 is a crucial event in neuronal death following global and focal ischemia and $\mathrm{HI}$ in the brain. The number of caspase-3-positive and Beclin1-positive cells in the penumbra of rats challenged by focal cerebral ischemia is elevated at $6-24 \mathrm{~h}$ by immunohistochemical double staining. Semi-quantitative assessment shows that approximately $30 \%$ of cells in the penumbra present both the activation of caspase- 3 and the up-regulation of Beclin1, indicating that autophagy and apoptosis interact with each other in the penumbra following focal cerebral ischemia ${ }^{[15]}$. An increase in Beclin1 expression colocalized with the activation of caspase-3 in neurons has also been found in neonatal cerebral $\mathrm{HI}^{[12]}$. In addition, there are dying neurons with numerous autophagosomes in their cytosol beginning $6 \mathrm{~h}$ after HI. However, these neurons never exhibit the morphology of pure autophagic cell death but show features of apoptosis, and cortical neurons with strong lysosomal expression (LAMP1 labeling) also express cleaved caspase- $3^{[13]}$. Furthermore, Atg7 deficiency largely prevents caspase-dependent death of pyramidal neurons in the neonatal hippocampus after severe hypoxic-ischemic injury ${ }^{[2]}$. These results indicate that the simultaneous activation of autophagic and apoptotic mechanisms can occur in the same dying neuron. Therefore, a new term of cell death "Apophagy" from apoptosis and autophagy, a kind of apoptotic cell death with a concomitant up-regulation of Beclin1 and activation of caspase-3, has been introduced ${ }^{[63]}$. Moreover, neurons presenting strong autophagic features in the border of the lesion $24 \mathrm{~h}$ after $\mathrm{HI}$ are TdT-mediated dUTP-biotin nick end labeling (TUNEL)-negative and display moderate chromatin condensation without being pyknotic, which suggests that autophagy precedes apoptosis and might even initiate apoptosis.

Ischemia-induced APL activation may cause neuronal and astrocytic apoptotic cell death through the cathepsin-caspase signaling pathway. Cathepsins are acidic endopeptidases, which belong to the papain superfamily of proteases ${ }^{[64]}$. Under physiologic conditions, their activity is restricted to the lysosomal compartment, where they participate in protein turnover by degrading unneeded proteins into amino acids ${ }^{[6]}$. It has been demonstrated that cerebral ischemia induces the release of cathepsins into the cytoplasm, where they extensively perform their proteolytic function and can promote ischemia-induced apoptosis through alterations of mitochondrial homeostasis and the activation of proapoptotic members of the Bcl-2 family ${ }^{[7,8,66,67]}$. Cathepsin B possesses a caspaseprocessing activity, which mainly appears on caspase-11 and caspase-1. Caspase-1 and caspase-11 play important roles in brain ischemia by promoting both apoptotic and inflammatory processes. In addition, cathepsin B proteolytic effects 
also include the activation of Bax and Bak, two proapoptotic members of the Bcl-2 family, and the subsequent release of cytochrome $c$ through permeabilization of the mitochondrial membrane. Cytochrome $c$ is a key activator of the apoptosome, which regulates the mitochondrial caspase activation pathway mediated by caspase-9 $9^{[66]}$. Cathepsin L can activate caspase-3, and cathepsin D can activate caspase-8. The inhibition of cathepsins leads to significant neuroprotection in a cathepsin-caspase dependent manner in the experimental model of stroke $\mathrm{e}^{[6,68-71]}$. Therefore, ischemia-induced ALP activation may be involved in neuronal and astrocytic apoptotic cell death via a cathepsin-caspase dependent manner in ischemic brain injury.

On the other hand, there is a crosstalk between autophagy and apoptosis in Bcl-2 levels after cerebral ischemia. The Bcl-2 protein family was initially characterized as apoptotic cell death regulators, but it has recently become clear that they also control autophagy because they can inhibit Beclin1-dependent autophagy ${ }^{[72-74]}$. The anti-apoptotic proteins of the Bcl-2 family constitutively interact with Beclin1, which serve as inhibitors of autophagy. Bcl-2 can block caspase-independent cell death and mitochondrial degradation and the two processes involved in autophagy. In growth factor-deprived neural progenitor cells and serum and potassium-deprived cerebellar granule cells, overexpression of Bcl-2 inhibits autophagy. Our findings show that the cerebral ventricular microinjection of autophagy inhibitor 3-MA, Baf, or Z-FA-fmk, can block ischemia-induced Bcl-2 degradation in a rat model of pMCAO and suppress OGD-induced Bcl-2 degradation in primary cultured astrocytes. Taken together, ischemia-induced APL activation may cause neuronal and astrocytic apoptotic cell death via regulating Bcl-2.

\section{Autophagy activation participates in cerebral ischemia-induced necrosis}

Some suggest that autophagy blockage may interrupt the activation of the apoptotic process and switch the mechanism of cell death from apoptosis to necrosis. As mentioned above, 3-MA and wortmannin, which inhibit autophagy, significantly reduce the expression of Beclin1 and augment the number of necrotic cells in the rat model of neonatal cerebral HI, indicating that when autophagy is blocked, neurons rapidly progress toward necrosis ${ }^{[75]}$. However, a growing body of evidence reveals that autophagy is required for necrotic cell death. Recently, Samara et al have reported overlap between autophagic and necrotic cell death. Utilizing an exceptionally well-characterized and genetically tractable model of necrotic neuronal cell death in $C$ elegans, they found that excessive autophagosome formation is induced early during necrotic cell death in $C$ elegans neurons and that autophagy is required for neuronal necrotic cell death. Impairment of autophagy by genetic inactivation of autophagy genes or by pharmacological treatment suppresses necrosis. Autophagy synergizes with lysosomal catabolic mechanisms to further facilitate neuronal necrotic cell death. Further studies reveal that calpain protease activity is also required for necrosis in $C$ elegans neurons and induces autophagy in neuronal necrotic cell death ${ }^{[76]}$. Taken together, activation of autophagy may be associated with neuronal or astrocytic necrotic death following cerebral ischemia. However, this still needs to be further confirmed in the many animal models of cerebral ischemia.

\section{Autophagy is a response to necroptotic cell death}

Experiments using a specific necroptotic inhibitor, necrostatin-1 (Nec-1), and one of its derivatives, 7-chloroindolenecrostatin-1 (7-Cl-Nec-1), have confirmed that necroptosis is involved in the ischemic brain injury induced by focal cerebral ischemia and neonatal $\mathrm{HI}^{[14,77]}$. The protection effect of $7-\mathrm{Cl}-\mathrm{Nec}-1$ is readily detectable, even when the compound is administered $6 \mathrm{~h}$ after the onset of cerebral ischemic injury ${ }^{[14]}$, at which point the administration of zVAD-fmk no longer decreases infarct volume ${ }^{[78]}$, indicating that necroptosis may participate in ischemia-induced delayed cell death. LC3-II is clearly induced after ischemic cerebral injury, but it does not reach its maximal level until $8 \mathrm{~h}$ post-MCAO, and delayed injection of 7-Cl-Nec-1 at $4 \mathrm{~h}$ and $6 \mathrm{~h}$ postocclusion still efficiently blocks the increase of LC3-II at the $8 \mathrm{~h}$ time point, confirming that the late induction of LC3-II in vivo indeed reflects the delayed activation of necroptosis.

In in vitro experiments, autophagy vesicles are commonly observed in necroptotic cells, leading some to propose that autophagy is an execution mechanism for necroptosis. In L929 cells, treatment with autophagy inhibitors 3-MA and wortmanin is able to partially inhibit zVAD-induced cell death. Knockdown of autophagy-related genes, such as Beclin1 and Atg7, is shown to be able to inhibit necroptosis in L929 cells ${ }^{[79]}$. However, in other cell types, this finding has not been supported. Jurkat cells, BALB/c mouse embryonic fibroblast cells (Balb c/3T3 cells), and mouse embryonic fibroblast cells (MEFs) have been extensively tested for the effect of autophagic inhibitors or the knockdown of Beclin1 and Atg5. None of these inhibitors of autophagy is able to reduce cell death $^{[14]}$.

Therefore, it remains to be determined if autophagy is actually a response to necroptotic cell death.

It is possible that autophagy plays dual roles in determining cell fate, depending on specific cell types and stimuli. It seems that physiological levels of autophagy caused by mild or moderate cerebral ischemia and/or hypoxia appear to be protective via the production of energy to prevent cell necrosis by catabolism and inhibit cell apoptosis by removing damaged mitochondria. However, high levels of autophagy caused by severe cerebral ischemia and/or hypoxia (focal cerebral ischemia or severe HI) may lead to self-digestion and eventual cell death (Figure 4).

\section{Outlook}

Initial neuroprotective clinical stroke trials primarily used antiexcitotoxic drugs to limit acute calcium-mediated injury attributable to cerebral ischemia. However, the excitotoxic phase mediated by the release of excitatory acids into the brain peaks within 1 to $2 \mathrm{~h}$ after ischemia, and treatments with anti- 
excitotoxic drugs are only effective when given within 1 to $2 \mathrm{~h}$ after focal ischemia in animal models ${ }^{[80]}$. Considering that the median hospital arrival time for stroke patients is 3 to $6 \mathrm{~h}^{[81]}$ and all of the trials of antiexcitotoxic drugs have been used to treat patients up to at least $6 \mathrm{~h}$ after the onset of symptoms, the negative outcomes of the 35 completed trials of antiexcitotoxic agents are not surprising. In the development of new therapies, focus must be placed on targets producing long-lasting protection and efficacy even when treatments are given during or at the 4 to $6 \mathrm{~h}$ after symptom onset, which is when patients generally arrive at the hospital. Therefore, a promising strategy for the development of such therapeutics is to inhibit the mechanisms that destabilize mitochondria via targeting prodeath signaling upstream of mitochondrial damage. APL activation regulates neural cell death mainly through cathepsinmediated mitochondrial damage. One of the mechanisms of the regulation of neural cell death by APL activation is the activation of the cathepsin-mediated mitochondrial apoptotic pathway, and 3-MA can reduce infarct volume even when administered $4 \mathrm{~h}$ after ischemia onset, indicating that 3-MA may have a wide therapeutic window. Therefore, 3-MA might have the potential to exhibit long-lasting protection in the clinic, targeting APL to develop stroke therapeutics. However, more work is required to determine the requirements under which the activation of autophagy reflects a protective or harmful response in cerebral ischemia. A profound understanding of the biological effects and the mechanisms underlying ischemia-induced autophagy in neurons and astrocytes might be helpful in seeking effective new treatment for ischemic brain injury.

\section{Acknowledgements}

This work is supported by grants from the National Natural Science Foundation of China (No 30973510) and the Scien- tific Research Foundation for the Returned Overseas Chinese Scholars, State Education Ministry.

\section{References}

1 Komatsu M, Waguri S, Ueno T, Iwata J, Murata S, Tanida I, et al. Impairment of starvation-induced and constitutive autophagy in Atg7deficient mice. J Cell Biol 2005; 169: 425-34.

2 Kuma A, Hatano M, Matsui M, Yamamoto A, Nakaya $\mathrm{H}$, Yoshimori T, et al. The role of autophagy during the early neonatal starvation period. Nature 2004; 432: 1032-6.

3 Shintani T, Klionsky DJ. Autophagy in health and disease: a doubleedged sword. Science 2004; 306: 990-5.

4 Canu N, Tufi R, Serafino AL, Amadoro G, Ciotti MT, Calissano P. Role of the autophagic-lysosomal system on low potassium-induced apoptosis in cultured cerebellar granule cells. J Neurochem 2005; 92: 122842.

5 Clarke PG. Developmental cell death: morphological diversity and multiple mechanisms. Anat Embryol (Berl) 1990; 181: 195-213.

6 Ohsawa Y, Isahara K, Kanamori S, Shibata M, Kametaka S, Gotow $\mathrm{T}$, et al. An ultrastructural and immunohistochemical study of PC12 cells during apoptosis induced by serum deprivation with special reference to autophagy and lysosomal cathepsins. Arch Histol Cytol 1998; 61: 395-403.

7 Uchiyama Y. Autophagic cell death and its execution by lysosomal cathepsins. Arch Histol Cytol 2001; 64: 233-46.

8 Nitatori T, Sato N, Waguri S, Karasawa Y, Araki H, Shibanai K, et al. Delayed neuronal death in the CA1 pyramidal cell layer of the gerbil hippocampus following transient ischemia is apoptosis. J Neurosci 1995; 15: 1001-11.

9 Zhu C, Wang X, Xu F, Bahr BA, Shibata M, Uchiyama Y, et al. The influence of age on apoptotic and other mechanisms of cell death after cerebral hypoxia-ischemia. Cell Death Differ 2005; 12: 162-76.

10 Zhu C, Xu F, Wang X, Shibata M, Uchiyama Y, Blomgren K, et al. Different apoptotic mechanisms are activated in male and female brains after neonatal hypoxia-ischaemia. J Neurochem 2006; 96: 1016-27.

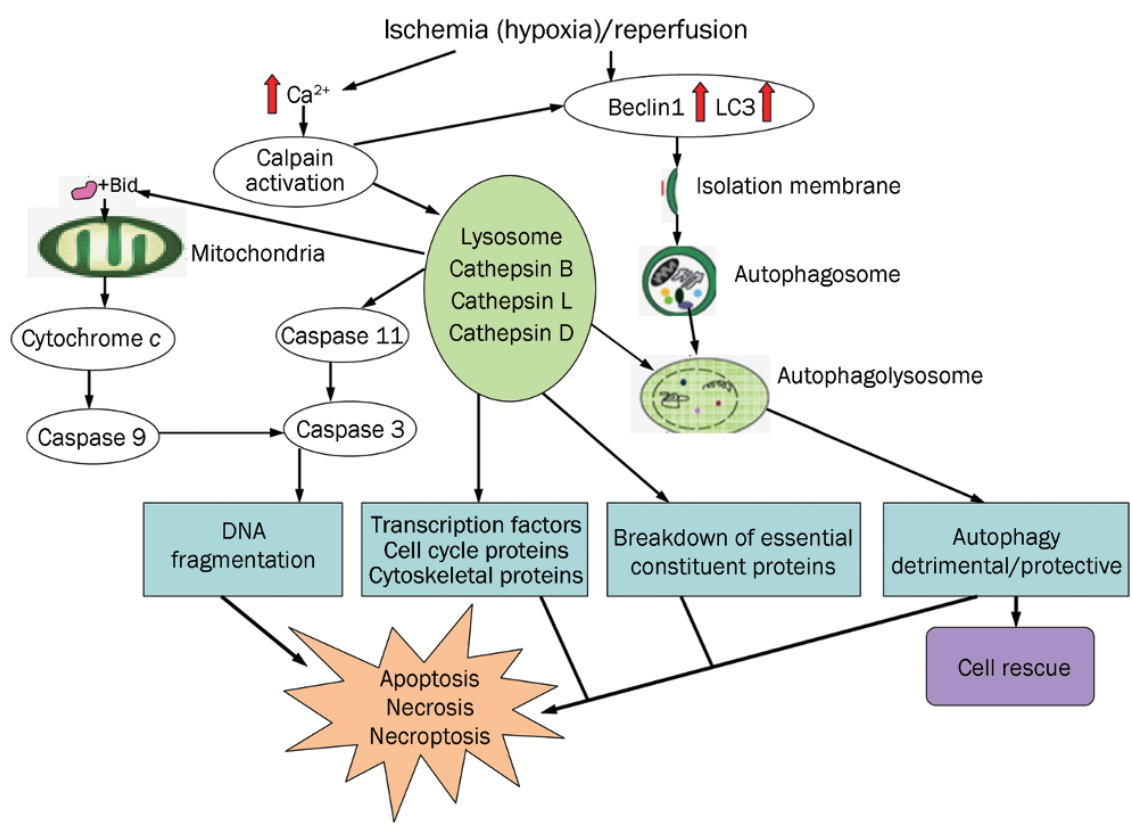

Figure 4. Roles of autophagy activation in neural cell survival and death in ischemic cerebral injury ${ }^{[63]}$. Cerebral ischemia (or hypoxia) and/or reperfusion induces the up-regulation of Beclin1 and LC3 and activates APL. APL activation either rescues the injured neural cells or induces cell death by necrosis, necroptosis, or apoptosis. 
11 Adhami F, Liao G, Morozov YM, Schloemer A, Schmithorst VJ, Lorenz $\mathrm{JN}$, et al. Cerebral ischemia-hypoxia induces intravascular coagulation and autophagy. Am J Pathol 2006; 169: 566-83.

12 Carloni S, Buonocore G, Balduini W. Protective role of autophagy in neonatal hypoxia-ischemia induced brain injury. Neurobiol Dis 2008; 32: 329-39.

13 Ginet V, Puyal J, Clarke PG, Truttmann AC. Enhancement of autophagic flux after neonatal cerebral hypoxia-ischemia and its regionspecific relationship to apoptotic mechanisms. Am J Pathol 2009; 175: 1962-74.

14 Degterev A, Huang Z, Boyce M, Li Y, Jagtap P, Mizushima N, et al. Chemical inhibitor of nonapoptotic cell death with therapeutic potential for ischemic brain injury. Nat Chem Biol 2005; 1: 112-9.

15 Rami A, Langhagen A, Steiger S. Focal cerebral ischemia induces upregulation of Beclin1 and autophagy-like cell death. Neurobiol Dis 2008; 29: 132-41.

16 Puyal J, Vaslin A, Mottier V, Clarke PG. Postischemic treatment of neonatal cerebral ischemia should target autophagy. Ann Neurol 2009; 66: 378-89.

17 Wen YD, Sheng R, Zhang LS, Han R, Zhang X, Zhang XD, et al. Neuronal injury in rat model of permanent focal cerebral ischemia is associated with activation of autophagic and lysosomal pathways. Autophagy 2008; 4: 762-9.

18 Qin AP, Liu CF, Qin YY, Hong LZ, Xu M, Yang L, et al. Autophagy was activated in injured astrocytes and mildly decreased cell survival following glucose and oxygen deprivation and focal cerebral ischemia. Autophagy 2010; 6: 738-53.

19 Lockshin RA, Zakeri Z. Caspase-independent cell death? Oncogene 2004; 23: 2766-73.

20 Jaattela M, Tschopp J. Caspase-independent cell death in T lymphocytes. Nat Immunol 2003; 4: 416-23.

21 Klionsky DJ, Abeliovich H, Agostinis P, Agrawal DK, Aliev G, Askew DS, et al. Guidelines for the use and interpretation of assays for monitoring autophagy in higher eukaryotes. Autophagy 2008; 4: 151-75.

22 Singh R, Kaushik S, Wang Y, Xiang Y, Novak I, Komatsu M, et al. Autophagy regulates lipid metabolism. Nature 2009; 458: 1131-5.

23 Todde V, Veenhuis M, van der Klei IJ. Autophagy: principles and significance in health and disease. Biochim Biophys Acta 2009; 1792: 3-13.

24 Rice JE 3rd, Vannucci RC, Brierley JB. The influence of immaturity on hypoxic-ischemic brain damage in the rat. Ann Neurol 1981; 9: 131-41.

25 Hu BR, Liu CL, Ou-yang Y, Blomgren K, Siesjo BK. Involvement of caspase 3 in cell death after hypoxia-ischemia declines during brain maturation. J Cereb Blood Flow Metab 2000; 20: 1294-300.

26 Romero AA, Gross SR, Cheng KY, Goldsmith NK, Geller HM. An agerelated increase in resistance to DNA damage-induced apoptotic cell death is associated with development of DNA repair mechanisms. J Neurochem 2003; 84: 1275-87.

27 Towfighi J, Mauger D, Vannucci RC, Vannucci SJ. Influence of age on the cerebral lesions in an immature rat model of cerebral hypoxiaischemia: a light microscopic study. Brain Res Dev Brain Res 1997; 100: 149-60.

28 Yager JY, Shuaib A, Thornhill J. The effect of age on susceptibility to brain damage in a model of global hemispheric hypoxia-ischemia. Brain Res Dev Brain Res 1996; 93: 143-54.

29 Sutherland GR, Dix GA, Auer RN. Effect of age in rodent models of focal and forebrain ischemia. Stroke 1996; 27: 1663-7; discussion 1668.

30 Papadopoulos MC, Koumenis IL, Yuan TY, Giffard RG. Increasing vulnerability of astrocytes to oxidative injury with age despite constant antioxidant defenses. Neuroscience 1998; 82: 915-25.

31 McDonald JW, Silverstein FS, Johnston MV. Neurotoxicity of $\mathrm{N}$-methyl$D$-aspartate is markedly enhanced in developing rat central nervous system. Brain Res 1988; 459: 200-3.

32 Adelson PD, Kochanek PM. Head injury in children. J Child Neurol 1998; 13: 2-15.

33 MacLusky NJ, Naftolin F. Sexual differentiation of the central nervous system. Science 1981; 211: 1294-302.

34 Rossi DJ, Brady JD, Mohr C. Astrocyte metabolism and signaling during brain ischemia. Nat Neurosci 2007; 10: 1377-86.

35 Hansson MJ, Mansson R, Morota S, Uchino H, Kallur T, Sumi T, et al. Calcium-induced generation of reactive oxygen species in brain mitochondria is mediated by permeability transition. Free Radic Biol Med 2008; 45: 284-94.

$36 \mathrm{Yu} \mathrm{JH}, \mathrm{Kim} \mathrm{KH}, \mathrm{Kim} \mathrm{H}$. Role of NADPH oxidase and calcium in cerulein-induced apoptosis: involvement of apoptosis-inducing factor. Ann N Y Acad Sci 2006; 1090: 292-7.

37 Kato H, Kogure K, Nakata N, Araki T, Itoyama Y. Facilitated recovery from postischemic suppression of protein synthesis in the gerbil brain with ischemic tolerance. Brain Res Bull 1995; 36: 205-8.

38 Nowak TS, Fried RL, Lust WD, Passonneau JV. Changes in brain energy metabolism and protein synthesis following transient bi-lateral ischemia in the gerbil. J Neurochem 1985; 44: 487-94.

39 Kumar R, Azam S, Sullivan JM, Owen C, Cavener DR, Zhang P, et al. Brain ischemia and reperfusion activates the eukaryotic initiation factor 2a kinase, PERK. J Neurochem 2001; 77: 1418-21.

40 Althausen S, Mengesdorf T, Mies G, Olah L, Nairn AC, Proud CG, et al. Changes in the phosphorylation of initiation factor elF-2alpha, elongation factor eEF-2 and p70 S6 kinase after transient focal cerebral ischaemia in mice. J Neurochem 2001; 78: 779-87.

41 Parsons JT, Churn SB, DeLorenzo RJ. Ischemia-induced inibition of calcium uptake into rat brain microsomes mediated by $\mathrm{Mg}^{2+} / \mathrm{Ca}^{2+}$ ATPase. J Neurochem 1997; 68: 1124-34.

$42 \mathrm{Hu}$ BR, Martone ME, Jones YZ, Liu CL. Protein aggregation after transient cerebral ischemia. J Neurosci 2000; 20: 3191-9.

43 Kitao Y, Ozawa K, Miyazaki M, Tamatani M, Kobayashi T, Yanagi H, et al. Expression of the endoplasmic reticulum molecular chaperone (ORP150) rescues hippocampal neurons from glutamate toxicity. J Clin Invest 2001; 108: 1439-50.

44 Yorimitsu T, Nair U, Yang Z, Klionsky DJ. Endoplasmic reticulum stress triggers autophagy. J Biol Chem 2006; 281: 30299-304.

45 Li J, Ni M, Lee B, Barron E, Hinton DR, Lee AS. The unfolded protein response regulator GRP78/BiP is required for endoplasmic reticulum integrity and stress-induced autophagy in mammalian cells. Cell Death Differ 2008; 15: 1460-71.

46 Choi KC, Kim SH, Ha JY, Kim ST, Son JH. A novel mTOR activating protein protects dopamine neurons against oxidative stress by repressing autophagy related cell death. J Neurochem 2010; 112: 366-76.

47 Zukor H, Song W, Liberman A, Mui J, Vali H, Fillebeen C, et al. HO-1mediated macroautophagy: a mechanism for unregulated iron deposition in aging and degenerating neural tissues. J Neurochem 2009; 109: 776-91.

48 Lee SJ, Cho KS, Koh JY. Oxidative injury triggers autophagy in astrocytes: the role of endogenous zinc. Glia 2009; 57: 1351-61.

49 Wang Y, Dong XX, Cao Y, Liang ZQ, Han R, Qin ZH, et al. p53 induction contributes to excitotoxic neuronal death in rat striatum through apoptotic and autophagic mechanisms. Eur J Neurosci 2009; 30: 2258-70.

50 Gupta S, Barrett T, Whitmarsh AJ, Cavanagh J, Sluss HK, Derijard $B$, et al. Selective interaction of JNK protein kinase isoforms with 
transcription factors. EMBO J 1996; 15: 2760-70.

51 Waetzig V, Herdegen T. Context-specific inhibition of JNKs: overcoming the dilemma of protection and damage. Trends Pharmacol Sci 2005; 26: 455-61.

52 Yang DD, Kuan CY, Whitmarsh AJ, Rincon M, Zheng TS, Davis RJ, et al. Absence of excitotoxicity induced apoptosis in the hippocampus of mice lacking the Jnk3 gene. Nature 1997; 389: 865-70.

53 Centeno C, Repici M, Chatton JY, Riederer BM, Bonny C, Nicod P, et al. Role of the JNK pathway in NMDA-mediated excitotoxicity of cortical neurons. Cell Death Differ 2006; 14: 240-53.

54 Arthur PG, Matich GP, Pang WW, Yu DY, Bogoyevitch MA. Necrotic death of neurons following an excitotoxic insult is prevented by a peptide inhibitor of c-jun N-terminal kinase. J Neurochem 2007; 102: 65-76.

55 Guan QH, Pei DS, Liu XM, Wang XT, Xu TL, Zhang GY. Neuroprotection against ischemic brain injury by SP600125 via suppressing the extrinsic and intrinsic pathways of apoptosis. Brain Res 2006; 1092: 36-46.

56 Hirt L, Badaut J, Thevenet J, Granziera C, Regli L, Maurer F, et al. D-JNKI1, a cell-penetrating c-Jun-N-terminal kinase inhibitor, protects against cell death in severe cerebral ischemia. Stroke 2004; 35: 1738-43.

57 Guan QH, Pei DS, Zong YY, Xu TL, Zhang GY. Neuroprotection against ischemic brain injury by a small peptide inhibitor of c-Jun N-terminal kinase (JNK) via nuclear and non-nuclear pathways. Neuroscience 2006b; 139: 609-27.

58 Ginet V, Puyal J, Magnin G, Clarke PGH, Truttmann AC. Limited role of the c-Jun $\mathrm{N}$-terminal kinase pathway in a neonatal rat model of cerebral hypoxia-ischemia. J Neurochem 2009; 108: 552-62.

59 Hara T, Nakamura K, Matsui M, Yamamoto A, Nakahara Y, SuzukiMigishima R, et al. Suppression of basal autophagy in neural cells causes neurodegenerative disease in mice. Nature 2006; 441: 8859.

60 Komatsu M, Waguri S, Chiba T, Murata S, Iwata J, Tanida I, et al. Loss of autophagy in the central nervous system causes neurodegeneration in mice. Nature 2006; 441: 880-4.

61 Zheng YQ, Liu JX, Li XZ, Xu L, Xu YG. RNA interference-mediated downregulation of Beclin1 attenuates cerebral ischemic injury in rats. Acta Pharmacol Sin 2009; 30: 919-27.

62 Uchiyama Y, Koike M, Shibata M. Autophagic neuron death in neonatal brain ischemia/hypoxia. Autophagy 2008; 4: 404-8.

63 Rami A, Kögel D. Apoptosis meets autophagy-like cell death in the ischemic penumbra: two sides of the same coin? Autophagy 2008; 4: 422-6.

64 Turk B, Turk V, Turk D. Structural and functional aspects of papainlike cysteine proteinases and their protein inhibitors. Biol Chem 1997; 378: 141-50.

65 Kirschke H, Langner J, Reimann S, Weideranders B, Ansorge S, Bohley P. Lysosomal cystein propteinases. In: protein degradation in health and disease, Ciba Foundation Symposium (Evered D, Whelan J, eds). Amsterdam: Excerpta Medica 1980; pp5-35.

66 Benchoua A, Braudeau J, Reis A, Couriaud C, Onténiente B. Activation of proinflammatory caspases by cathepsin B in focal cerebral ischemia. J Cereb Blood Flow Metab 2004; 24: 1272-9.

67 Unal-Cevik I, Kilinç M, Can A, Gürsoy-Ozdemir Y, Dalkara T. Apoptotic and necrotic death mechanisms are concomitantly activated in the same cell after cerebral ischemia. Stroke 2004; 35: 2189-94.

68 Seyfried DM, Veyna R, Han Y, Li K, Tang N, Betts RL, et al. A selective cysteine protease inhibitor is non-toxic and cerebroprotective in rats undergoing transient middle cerebral artery ischemia. Brain Res 2001; 901: 94-101.

69 Hou Q, Ling L, Wang F, Xing S, Pei Z, Zeng J. Endostatin expression in neurons during the early stage of cerebral ischemia is associated with neuronal apoptotic cell death in adult hypertensive rat model of stroke. Brain Res 2010; 1311: 182-8.

70 Yoshida M, Yamashima T, Zhao L, Tsuchiya K, Kohda Y, Tonchev $A B$, et al. Primate neurons show different vulnerability to transient ischemia and response to cathepsin inhibition. Acta Neuropathol 2002; 104: 267-72.

71 Yamashima T, Kohda Y, Tsuchiya K, Ueno T, Yamashita J, Yoshioka T, et al. Inhibition of ischaemic hippocampal neuronal death in primates with cathepsin B inhibitor CA-074: a novel strategy for neuroprotection based on 'calpain-cathepsin hypothesis'. Eur J Neurosci 1998; 10: 1723-33.

72 Levine B, Yuan J. Autophagy in cell death: an innocent convict? J Clin Invest 2005; 115: 2679-88.

73 Levine B, Sinha S, Kroemer G. Bcl2 family members: dual regulators of apoptosis and autophagy. Autophagy 2008; 4: 600-6.

74 Pattingre S, Tassa A, Qu X, Garuti R, Liang XH, Mizushima N, et al. $\mathrm{Bcl} 2$ antiapoptotic proteins inhibit Beclin1-dependent autophagy. Cell 2005; 122: 927-39.

75 Balduini W, Carloni S, Buonocore G. Autophagy in hypoxia-ischemia induced brain injury: evidence and speculations. Autophagy 2009; 5: 221-3.

76 Samara C, Syntichaki P, Tavernarakis N. Autophagy is required for necrotic cell death in Caenorhabditis elegans. Cell Death Differ 2008; 15: $105-12$

77 Northington FJ, Chavez-Valdez R, Graham EM, Razdan S, Gauda EB, Martin LJ. Necrostatin decreases oxidative damage, inflammation, and injury after neonatal HI. J Cereb Blood Flow Metab 2011; 31: 178-89.

78 Endres M, Namura S, Shimizu-Sasamata M, Waeber C, Zhang L, Gómez-Isla T, et al. Attenuation of delayed neuronal death mild focal ischemia in mice by inhibition of the caspase family. J Cereb Blood Flow Metab 1998; 18: 238-47.

79 Yu L, Alva A, Su H, Dutt P, Freundt E, Welsh S, et al. Regulation of an ATG7-becline1 program of autophagic cell death by caspase-8. Science 2004; 304: 1500-2.

80 Dirnagl U, ladecola C, Moskowitz MA. Pathobiology of ischaemic stroke: an integrated view. Trends Neurosci 1999; 22: 391-7.

81 Evenson KR, Rosamond WD, Morris DL. Prehospital and in-hospital delays in acute stroke care. Neuroepidemiology 2001; 20: 65-76.

82 Edinger AL, Thompson CB. Death by design: apoptosis, necrosis and autophagy. Curr Opin Cell Biol 2004; 16: 663-9. 